\title{
Renin Activation in the Venous Plasma from the Involved Kidney in the Patient with Renal Hypertension
}

\author{
Mohinder P. Sambhi and Charles E. Wiedeman \\ From the Department of Medicine, University of Southern California School of \\ Medicine, Los Angeles, California 90033
}

A B S T R A C T Measurements of plasma renin activity (PRA) in renal vein blood from the ischemic kidney are reported to be generally higher than from the contralateral kidney. Importance of factors other than renin content of renal venous plasma has not been investigated. Initial rate measurements of angiotensin generation with added excess of homologous renin (Plasma Renin Substrate Activity [PRSA]-20 min) were made in bilateral renal venous plasma from 31 patients suspected of suffering from unilateral renal hypertension. The mean values from the involved vs. the contralateral kidney were 551 vs. $331 \mathrm{ng}$ respectively of angiotensin II equivalents generated per milliliter of plasma per 20 min of incubation. The measurement of maximal angiotensin generation under the same conditions with incubation prolonged to $3 \mathrm{hr}$ (PRSA-180 $\mathrm{min}$ ), however, were bilaterally equal in renal venous plasma from selected patients with renal hypertension who showed distinct differences in PRSA-20 min and PRA measurements. Prior extraction of plasma lipids did not significantly change the bilateral renal venous PRSA-20 min determinations. Stimulation of endogenous renin release in normal dogs did not change the PRSA determinations. The data suggest strongly the presence of a "renin activating" mechanism in the renal venous plasma from the involved kidney of patients with renal hypertension.

This work was presented in parts at the annual meetings of the Council for High Blood Pressure Research, Cleveland, Ohio, October 1970; at the Western Society for Clinical Research meetings at Carmel, California, January 1970; at the Annual meetings of the American Heart Association, Dallas, Texas, November 1969; and at the Fourth International Congress of Nephrology, Stockholm, June 1969.

Dr. Sambhi's present address is Chief, Division of Hypertension-Medical Service, Veterans Administration Hospital, 16111 Plummer, Sepulveda, Calif. 91343.

Received for publication 17 May 1971 and in revised form 30 August 1971.

\section{INTRODUCTION}

Bilateral measurements of plasma renin activity ( $\mathrm{PRA}^{1}$ ) in renal venous blood have significantly aided the identification of the involved or the relatively more involved kidney in patients with renal hypertension (1-9). Varying degree of differential between the two renal venous PRA measurements (a ratio ranging from 1.7 to 3 and higher) has been regarded as significant. Unilateral elevation of PRA in the renal vein blood, however, has not been found to be a constant feature for all patients with surgically remediable renal hypertension. On the other hand, unilateral elevations of renal vein PRA, presumably unrelated to the hypertensive process, have been noted (3). The reported incidence of these false negative and false positive determinations has been around $21-37 \%(3,8)$. Also PRA values from the contralateral renal vein, as well as the peripheral blood in proven cases of renal hypertension, have been described as normal in some cases and elevated in others $(5,9)$. Direct pressor activity measurements of the venous effluent from the affected kidney in patients with renal hypertension have been proposed as a diagnostic tool superior to the measurements of renin content by one group of investigators (10). Others found it to be of lesser value (11).

In peripheral plasma of normal as well as hypertensive subjects, the existence of naturally occurring cofactors of renin reaction has been suggested by several workers (12-14) who observed a considerable variation in the rate of angiotensin generation in different samples during PRA measurements under constant in vitro conditions. A phospholipid inhibitor of renin, widely distributed in animal tissues and capable of reducing blood pressure of hypertensive animals, has been described (15-17). Any possible significance of this inhibitor or

${ }^{1}$ Abbreviations used in this paper: DFP, diisopropyfluorophosphonate; PRA, plasma renin activity; PRSA, plasma renin substrate activity. 
other unknown modifiers of renin-substrate reaction in health or disease, however, remains to be established. It is noteworthy that other investigators $(18,19)$, who have discounted the existence of renin cofactors, have used somewhat different methods for renin measurements in plasma that involved addition of exogenous renin substrate and thereby determined renin "concentration" rather than "activity."

In bilateral renal venous plasma from renal hypertensive patients, comparisons of renin activity vs. concentration measurements have not been reported in the literature. Also, data on differential measurements of renin substrate concentration or activity in the bilateral renal venous plasma is lacking. The present studies on bilateral renal venous plasma from patients with renal hypertension were, therefore, designed to answer the following question: Apart from the well-known bilateral difference in renin concentration implied in activity measurements and demonstrable in approximately $75 \%$ of the patients with renal hypertension, can the influence of factors other than renin on in vitro generation of angiotensin in renal venous plasma be demonstrated or ruled out? The experimental approach used in these studies has centered around one assertion, that if the addition of equal amounts of exogenous renin to the bilateral renal venous plasma is made to achieve high enough rates of angiotensin generation, the influence of existing difference in the level of endogenous renin on angiotensin generation can be taken as masked and nullified. Under these conditions, bilateral angiotensin generation should practically equalize, provided the concentration of renin substrate is equal in bilateral renal venous plasma and there are no inhibitors or activators of renin reaction.

\section{METHODS}

Blood was collected from patients in precooled test tubes (siliconized glass or plastic) containing an amount of $15 \%$ ammonium EDTA to give a final concentration of $0.38 \%$. Plasma was separated in a refrigerated centrifuge and kept frozen until the time of use.

Plasma Renin Activity (PRA) measurements and studies on angiotensin generation with added excess of homologous renin were carried out using methods of Boucher, Veyrat, de Champlain, and Genest (12). In the case of dog plasma, a drop of $1 \%$ diisopropylfluorophosphonate (DFP) was added to the incubates in addition. Bioassay techniques for angiotensin using a $16 \mathrm{hr}$ nephrectomized, pentoliniumtreated rat have been described previously (20).

Renin from human kidneys was prepared according to the methods described by Haas, Goldblatt, Gipson, and Lewis (21). Human renin prepared according to these methods was found to be free from "angiotensinase" activity against angiotensin I and II. Variation among different batches of renin so prepared was remarkably small. Average weight of kidney tissue taken was $300 \mathrm{~g}$. Final volume of prepared renin was between 15 and $20 \mathrm{ml}$. Goldblatt assay of the preparation was approximately $2 \mathrm{U} / \mathrm{ml}$. Total protein content was between 20 and $21 \mathrm{mg} / \mathrm{ml}$. In addition, each batch of renin preparation was standardized in terms of its enzymatic activity. The product of renin reaction was confirmed to be immunoreactive angiotensin I by radioimmunoassay, and rat pressor bioassay results were expressed as ng equivalents of angiotensin II-amide. Approximately $300 \mathrm{ng}$ of angiotensin were produced, with $0.1 \mathrm{ml}$ of human renin preparation added to $1 \mathrm{ml}$ of a pooled sample of normal human plasma and incubated for $20 \mathrm{~min}$ according to Boucher et al. (12). Angiotensin production in plasma from hypertensive subjects under similar conditions usually ranged from 300 to $900 \mathrm{ng} / \mathrm{ml}$ per $20 \mathrm{~min}$. Dog renin was prepared by essentially similar but modified methods. In order to achieve complete freedom from angiotensinases the final preparation was treated with DFP (incubated $10 \mathrm{~min}$ with a few drops of $1 \%$ solution). Total protein content of dog renin preparations was somewhat higher $(30-35 \mathrm{mg} / \mathrm{ml})$ than human renin. Angiotensin production with $0.1 \mathrm{ml}$ of dog renin preparation was 275$450 \mathrm{ng} / \mathrm{ml}$ of normal dog plasma per $20 \mathrm{~min}$ of incubation time.

Excess of renin for the purpose of these studies was defined as the volume of renin preparation which on further increase did not enhance angiotensin generation expressed as per milliliter of normal and hypertensive plasma per 20 min of incubation time. For each batch of renin preparation, the volume of renin solution necessary to provide an excess was determined by an experiment as illustrated in Fig. 1.

Human renin substrate used in some of the studies was a crude plasma fraction $I_{B}$ (supplied by Hyland Laboratories, Los Angeles, Calif.) prepared by modified methods of Surgenor, Strong, Taylor, Gordon, and Gibson (22) using cold ethanol and ammonium sulfate precipitations.

Angiotensin generation with added excess of homologous renin. In the presence of added excess of the enzyme, the rate of the enzymatic reaction is principally proportional to the available concentration of the enzyme substrate provided no inhibitors or activators of the reaction are present (23). Since the presence or absence in human plasma of such cofactors of renin-substrate reaction is not established, the measurements of angiotensin generation in whole plasma with added excess of renin cannot be taken as the true index of the actual concentration of renin substrate. For these reasons we have preferred to call these determinations of angiotensin generation under the given conditions as plasma renin substrate activity (PRSA) measurements. The term PRSA used in the text has the further merit of being analogous to the term PRA used for plasma renin activity.

It was neither feasible nor entirely valid to perform conventional enzyme kinetic studies in crude renal venous plasma from individual patients. Instead, we have studied angiotensin generation for two time periods in whole plasma under the imposed conditions of incubation with added excess of angiotensinase-free homologous renin

(a) The initial rate measurements with short term incubations for $20 \mathrm{~min}$, termed PRSA-20 min, were selected as a more reliable index of the influence of the enzyme, as well as the substrate concentration on the rate of the reaction (23). Accordingly, in the presence of added excess of the enzyme, the rate of reaction during these short-term incubations should be proportional to either the available substrate concentrations alone (if no cofactors are operative) or in addition, reflect the influence of any existing modifiers of the rate of the reaction.

(b) The measurements of maximal angiotensin generation under the same conditions with longer incubation periods 


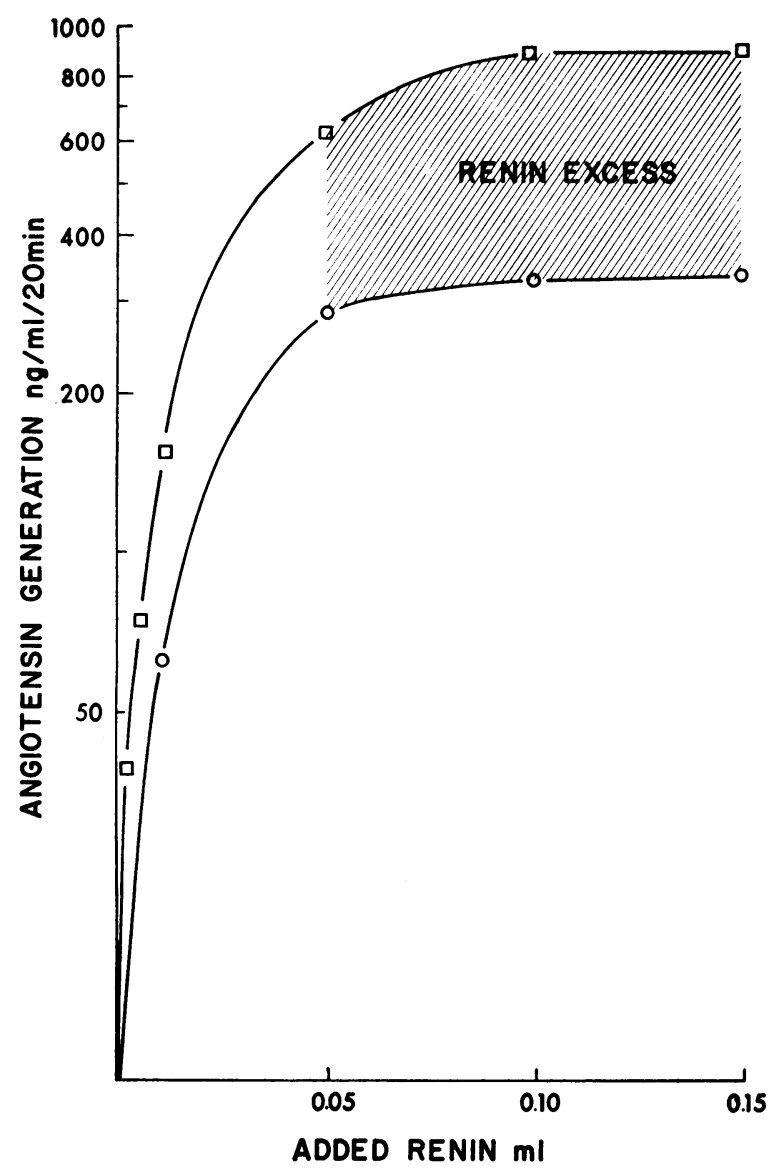

Figure 1 Angiotensin production in pooled samples of plasma from normal $(\mathrm{O}-\mathrm{O})$ and hypertensive $(\square-\square)$ subjects, plotted vs. levels of added renin (milliliters of preparation used) to determine the quantity of renin required to give maximum angiotensin yield.

of $3 \mathrm{hr}$ termed PRSA-180 min, were performed with the purpose of equating them, as best as possible under the existing conditions, to the total substrate concentration rather than the rate of renin-substrate reaction.

The volume of the standardized human renin preparation required to yield maximal rate of angiotensin generation per milliliter of plasma during PRSA measurements (Fig. 1) was generally $0.05 \mathrm{ml}$ and always between 0.05 and $0.1 \mathrm{ml}$. PRSA-20 min was determined in most of the patients. PRSA-180 min was determined in selected patients. Routine PRSA measurements were made on nondialysed whole plasma. In many samples of bilateral renal venous plasma effective dialysis against water followed by reconstitution to isotonicity with sodium chloride was shown not to cause significant change in the PRSA determinations.

Lipid extractions. Plasma $\mathrm{pH} 7.4$ was lyophilized and extracted three times at $0^{\circ} \mathrm{C}$ with purified acetone $(10$ volumes) followed by extraction twice with 5-10 volumes of anhydrous ether. The lipid extracts and the residual plasma were dried separately under vacuum. The plasma residue was reconstituted to original volume with deionized distilled water at $4^{\circ} \mathrm{C}$ and kept frozen until the time of incubations.
Stimulation of endogenous renin release. Normal male dogs weighing approximately $20 \mathrm{~kg}$ were obtained $2-3$ days before the day of the experiment. The dogs were anesthetized with approximately $20 \mathrm{mg} / \mathrm{kg}$ of sodium pentobarbitol. After obtaining control venous samples, one of the following stimuli or a combination thereof was used to provoke renin release in the experimental animal: (a) acute bleeding $600 \mathrm{ml}$. (b) intravenous drip infusion of sodium nitroprusside solution $100 \mu \mathrm{g} / \mathrm{ml}$ to lower and maintain the monitored mean intra-arterial blood pressure by $40-60 \mathrm{~mm} \mathrm{Hg}$. (c) intravenous injection of $40 \mathrm{mg}$ of furosemide (degree of natriuresis was not quantitated). $(d)$ Intravenous injection of $80 \mathrm{U}$ of regular insulin (the resulting hypoglycemia caused constant shaking and chills).

Each experimental period was $30 \mathrm{~min}$. Blood samples were collected before and after each period and processed as described above.

Clinical material. The term involved kidney or the more involved kidney was based both on a higher value of renal venous PRA as well as the available clinical diagnosis.

\section{RESULTS}

Initial rate measurements ( $P R S A-20 \mathrm{~min}$ ) of angiotensin generation with added excess of renin. Fig. 2 shows PRSA-20 min determinations on bilateral renal venous plasma in 23 patients with a clinical diagnosis of predominantly unilateral renal hypertension. Each determination represents an average value of two to four determinations. Standard error of the mean of the difference between duplicate PRSA-20 min determina-

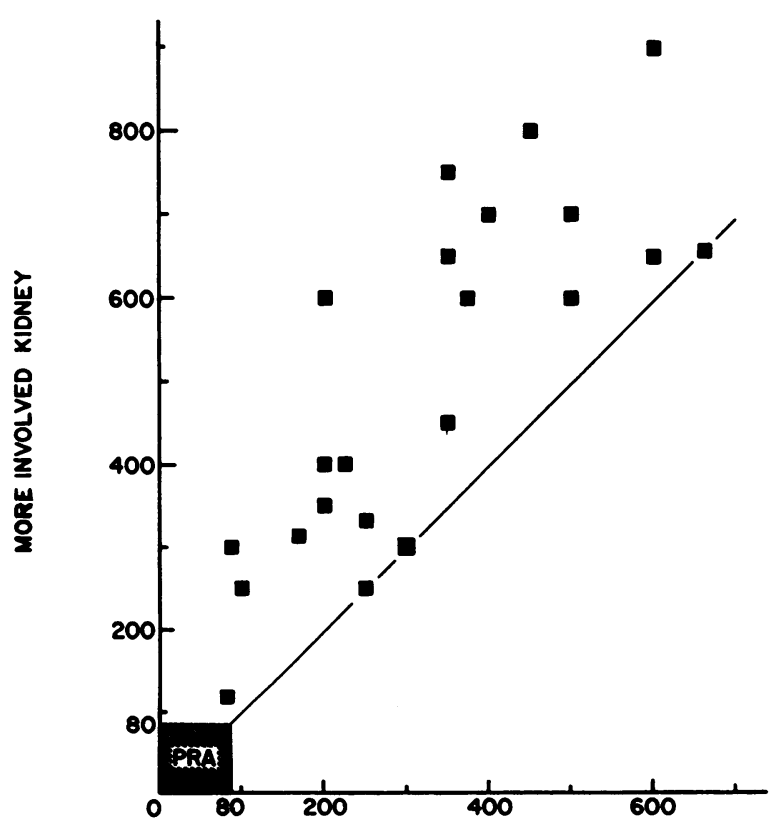

LESS INVOLVED KIDNEY

Figure 2 Angiotensin generation with added excess of human renin in $20 \mathrm{~min}$ of incubation time (PRSA-20 min) is compared in the renal venous plasma from the more involved vs. contralateral (less involved) kidney. 
tions on 22 plasma samples was 10.7 ( $\mathrm{sD} \pm 50 \mathrm{ng} / \mathrm{ml}$ ). In the left hand corner of Fig. 2, the square marked PRA shows the range of simultaneously measured plasma renin activity on the same scale but expressed as nanograms per milliliter per $3 \mathrm{hr}$ in $15^{2}$ of the same 23 patients including those showing the highest PRSA20 min values. Individual values of PRA measurements in these subjects are shown in Fig. 3. It should be noted (Figs. 2 and 3 ) that the range of angiotensin generation with added renin during PRSA-20 min measurements is amplified up to 900 -fold when compared with the scale of PRA values (incubation time $3 \mathrm{hr}$ ). It should be further noted that the PRSA-20 min values seem to lateralize existing bilateral differences in the renal venous plasma (Fig. 2) much better than do the PRA values (Fig. 3 ). While 10 of the 15 bilateral PRA determinations shown in Fig. 3 could be considered as showing an insignificant difference, only 6 out of 23 PRSA-20 min determinations appear to fall in this category including the range of the error $( \pm 50 \mathrm{ng})$ of the method.

Routine PRSA-20 min measurements were performed at plasma $\mathrm{pH} 5.5$ in conformity with measurements of PRA and PRSA-180 min. In several patients PRSA-20 min measurements were repeated at plasma $\mathrm{pH}$ of 7.5 . PRSA-20 min determinations, compared with each other at the two $\mathrm{pH}$ values, were similar in some plasma samples and somewhat different in others. The difference, however, lacked a consistent pattern. The values obtained at the neutral $\mathrm{pH}$ were scattered on both sides of those obtained at the acid $\mathrm{pH}$. Nevertheless, existing differences between bilateral renal venous PRSA-20 min noted at the acid $\mathrm{pH}$ were also present at the neutral $\mathrm{pH}$ and were of similar magnitude.

Measurements of maximal angiotensin generation (PRSA-180 min) with added excess of renin. Five patients with known renovascular hypertension (Fig. 4) were selected on the basis of a marked difference in PRA values between the bilateral renal venous plasma, and PRSA-180 min in renal venous plasma was studied in these patients. As shown in the upper panel of Fig. 4 , there is a very marked (average six to one) difference in the plasma renin activity in the renal venous blood obtained from the two kidneys. In the middle panel (Fig. 4) marked as added renin, PRSA-180 min expressed as nanograms of angiotensin per hour of incubation time, is practically equal in plasma from both renal veins. In the lower panel (Fig. 4) when both renin as well as substrate of human origin were added, angiotensin production again is significantly higher in renal venous plasma from the involved side. Under the

\footnotetext{
${ }^{2}$ Available bilateral renal venous plasma was insufficient to perform simultaneous PRA and PRSA determinations in the remaining patients.
}

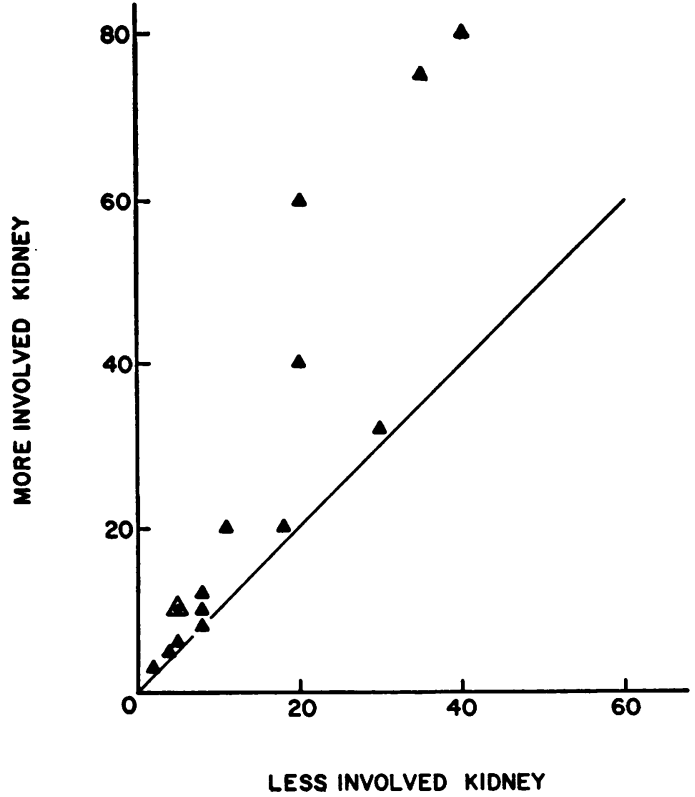

Figure 3 Comparison of bilateral renal venous PRA values (in nanograms/milliliter per $3 \mathrm{hr}$ ) in 15 of the patients shown in Fig. 2.

conditions of added excess of substrate, angiotensin generation can be assumed to be independent of the substrate concentration, and to be theoretically dependent upon the available concentration of enzyme and/or additional influence of "inhibitors" or "accelerators" of the enzymatic reaction.

These experiments indicated to us that the observed bilateral diffeernce in PRSA-20 min values shown in Fig. 2 in the renal venous plasma is probably not attributable to a difference in the concentration of renin substrate. Additional confirmatory studies, determining PRSA-20 $\mathrm{min}$ and PRSA-180 $\mathrm{min}$ simultaneously in the same subject, however, were required. The studies on 11 patients listed in Table I further support these findings. The mean of PRSA-20 min measurements was $739 \mathrm{ng}$ angiotensin/ $/ \mathrm{ml}$ plasma per $20 \mathrm{~min}$ in the renal venous blood from the presumably "involved" kidney (Table I), and $509 \mathrm{ng} / \mathrm{ml}$ per $20 \mathrm{~min}$ from the contralateral kidney. The mean of PRSA-180 min expressed as nanograms angiotensin per milliliter per $3 \mathrm{hr}$ however was 1340 and 1432 respectively. Excluding the patients with bilateral disease (patients No. 6, 10, and 11, marked with asterisk in Table I) the mean values for PRSA-20 min in the remaining eight patients with predominantly unilateral disease were $616 \mathrm{ng} / \mathrm{ml}$ and $337 \mathrm{ng} / \mathrm{ml}$, respectively in the effluent of the more involved and the less involved contralateral kidney. The mean of the corresponding figures for PRSA $180 \mathrm{~min}$ for the two kidneys remained $1506 \mathrm{ng} / \mathrm{ml}$ and $1630 \mathrm{ng} / \mathrm{ml}$ respectively. 


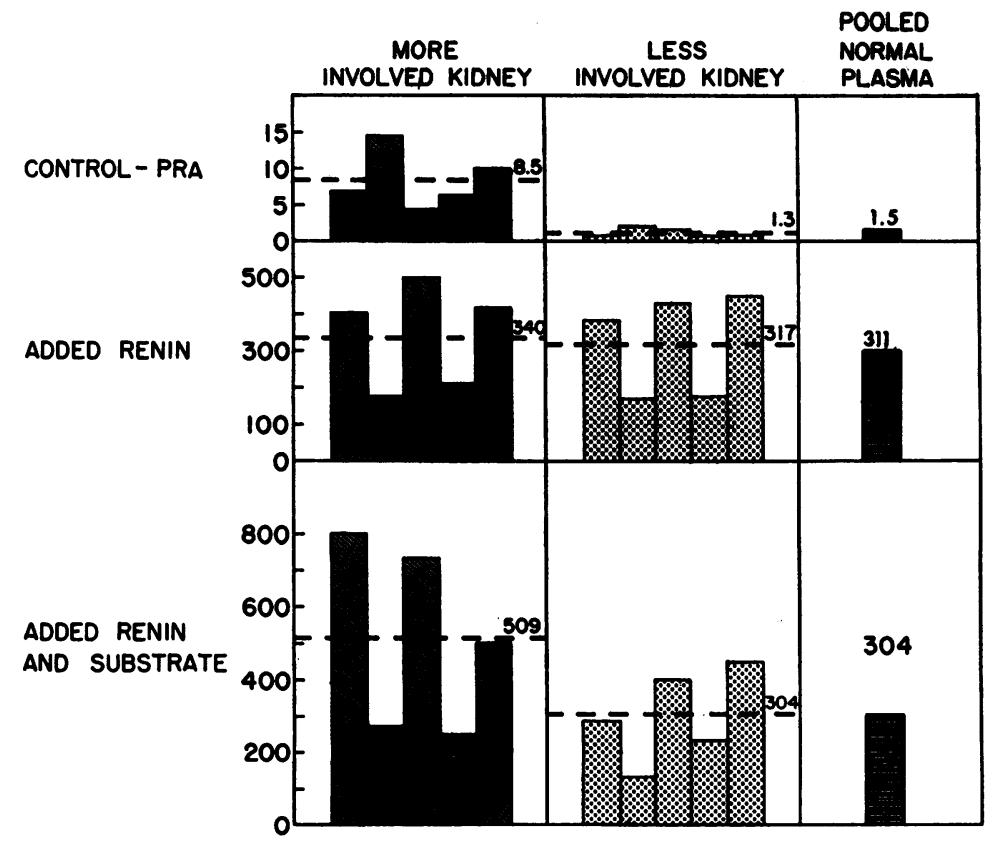

FIGURE 4 Angiotensin production ( $3 \mathrm{hr}$ incubation time) expressed as nanograms/milliliter plasma per hour of incubation time, in bilateral renal venous plasma from five patients with known unilateral renovascular hypertension is shown under three different conditions (see text). On the right hand side of each panel, values obtained in pooled normal peripheral venous plasma are shown for comparison. The upper panel shows endogenous renin activity. The middle panel with added renin represents PRSA-180 min measurements. In the lower panel, angiotensin generation is shown in the same plasma samples with added renin substrate, as well as added renin.

The results on the three patients with bilateral disease shown in Table I present an interesting and significant contrast. The PRSA-20 min measurements are bilaterally equal in the renal venous plasma from these patients and more importantly, are equal to the measurements of PRSA-180 min. If the renin substrate consumed in $20 \mathrm{~min}$ (PRSA-20 $\mathrm{min}$ ) is expressed as the percentage of the assumed total consumable substrate under the given conditions (PRSA-180 min), a highly pertinent index emerges that meaningfully differentiates between the pattern observed in the renal venous plasma from subjects with advanced bilateral vs. predominantly unilateral renal disease. The value can be appropriately termed as the Renin Activation Index and was $100 \%$ in plasma from both renal veins in bilateral disease. Equally pertinent is the difference in the renin activation index observed between the two renal vein plasma samples from eight subjects with predominantly unilateral disease with one, more or less, normal kidney. The calculated index using the mean values of the group shown in Table $I$ in the venous plasma from the more involved vs. the less involved kidney was $41 \%$ and $21 \%$ respectively.
Influence of endogenous renin concentration on PRSA measurements. It has been argued above that the excess of exogenous renin added to plasma during PRSA determinations is comparatively so large that the preexisting difference of endogenous renin concentrations between bilateral renal venous blood can hardly account for or contribute towards the observed differences of PRSA-20 min values between the two renal veins.

In order to establish whether or not PRSA values as determined are influenced by induced alterations in endogenous renin concentration, experiments were performed in five normal dogs. Acute renin release was induced, as described in the experimental section, by intravenous administration of a diuretic, increased sympathetic activity caused by insulin hypoglycemia, acute hypotension (nitroprusside), and blood loss. Plasma renin activity (PRA) and PRSA-20 min measurements (homologous renin added) were performed $30 \mathrm{~min}$ after each procedure and the results are shown in Fig. 5. In three dogs, the experiments included more than a single stimulus. Plasma renin activity, in almost all experiments, showed an increase ranging from a slight to a 
TABLE I

Measurement of the Initial Rate (PRSA-20 min) and the Maximal Angiotensin Generation (PRSA-180 min) with Added Excess of Human Renin in Bilateral Renal Venous Plasma in Patients with Renal Hypertension

\begin{tabular}{|c|c|c|c|c|c|c|c|c|c|}
\hline Subject & Age & Sex & \multicolumn{2}{|c|}{ Plasma sample } & PRSA & PRSA & PRA & & Clinical diagnosis \\
\hline & $y r$ & & & & $20 \mathrm{~min} / \mathrm{ml} /$ & $\begin{array}{l}\mathrm{ng} / \mathrm{ml} / \\
180 \mathrm{~min}\end{array}$ & $\begin{array}{c}n g / m l / \\
3 \mathrm{hr}\end{array}$ & & \\
\hline 2. L. M. & 27 & $\mathrm{~F}$ & \multicolumn{2}{|c|}{$\begin{array}{l}\text { Right R.V. } \\
\text { Left R.V. }\end{array}$} & $\begin{array}{r}70 \\
200\end{array}$ & $\begin{array}{l}700 \\
800\end{array}$ & $\begin{array}{l}3.0 \\
6.5\end{array}$ & \multicolumn{2}{|c|}{$\begin{array}{l}\text { Fibromuscular hyperplasia, left rena- } \\
\text { artery. }\end{array}$} \\
\hline 3. F. M. & 47 & $\mathbf{M}$ & \multicolumn{2}{|c|}{$\begin{array}{l}\text { Right R.V. } \\
\text { Left R.V. } \\
\text { I.V.C. }\end{array}$} & $\begin{array}{l}400 \\
900 \\
800\end{array}$ & $\begin{array}{l}1300 \\
1200 \\
1100\end{array}$ & $\begin{array}{r}8.8 \\
13.5 \\
12.5\end{array}$ & \multicolumn{2}{|c|}{$\begin{array}{l}\text { Hypertensive cardiovascular disease } \\
\text { Paresis-left, post poliomyelitis } \\
\text { Questionable renographic evidence } \\
\text { for mild impairment of right rena } \\
\text { function. No demonstrable rena } \\
\text { artery stenosis. }\end{array}$} \\
\hline 5. T. E. & 48 & $\mathbf{M}$ & \multicolumn{2}{|c|}{$\begin{array}{l}\text { Right R.V. } \\
\text { Left R.V. } \\
\text { I.V.C. }\end{array}$} & $\begin{array}{l}600 \\
800 \\
450\end{array}$ & $\begin{array}{l}500 \\
500 \\
600\end{array}$ & $\begin{array}{l}104.0 \\
250.0 \\
130.0\end{array}$ & \multicolumn{2}{|c|}{$\begin{array}{l}\text { Left renal artery stenosis, severe. } \\
\text { Hypertensive retinopathy, grade } \\
\text { III. Congestive heart failure. Ad- } \\
\text { vanced hypertensive cardiovascu- } \\
\text { lar disease. }\end{array}$} \\
\hline 6. T. H. & 46 & $\mathbf{M}$ & \multicolumn{2}{|c|}{$\begin{array}{l}\text { Right R.V. } \\
\text { Left R.V. } \\
\text { I.V.C. }\end{array}$} & $\begin{array}{r}1000 \\
900 \\
850\end{array}$ & $\begin{array}{l}900 \\
900 \\
800\end{array}$ & $\begin{array}{l}60.0 \\
50.0 \\
52.0\end{array}$ & \multicolumn{2}{|c|}{$\begin{array}{l}\text { Hypertensive cardiovascular disease. } \\
\text { Diabetes mellitus, mild. Arteriolar } \\
\text { nephrosclerosis. Mild azotemia. } \\
\text { Radiographic evidence of slight } \\
\text { deformity of the superior pole of } \\
\text { the right kidney. }\end{array}$} \\
\hline 10. M. A. & 54 & $\mathbf{M}$ & \multicolumn{2}{|c|}{$\begin{array}{l}\text { Right R.V. } \\
\text { Left R.V. } \\
\text { I.V.C. }\end{array}$} & $\begin{array}{r}1200 \\
1200 \\
850\end{array}$ & $\begin{array}{r}1000 \\
1000 \\
900\end{array}$ & $\begin{array}{l}13.0 \\
37.5 \\
12.5\end{array}$ & \multicolumn{2}{|c|}{$\begin{array}{l}\text { Hypertensive cardiovascular disease. } \\
\text { Left renal stag horn calculus lead- } \\
\text { ing to pyelitis and contracted } \\
\text { kidney. Renal artery stenosis, } \\
\text { bilateral. }\end{array}$} \\
\hline \multirow[t]{5}{*}{ 11. D. W. } & 54 & $\mathbf{M}$ & \multirow{2}{*}{\multicolumn{2}{|c|}{$\begin{array}{l}\text { Right R.V. } \\
\text { Left R.V. }\end{array}$}} & $\begin{array}{r}800 \\
1000\end{array}$ & $\begin{array}{l}800 \\
800\end{array}$ & $\begin{array}{l}85 \\
95\end{array}$ & \multicolumn{2}{|c|}{$\begin{array}{l}\text { Left renal artery stenosis, distal, } \\
\text { moderate. Right renal stone, lower } \\
\text { pole. Alcoholic cirrhosis. }\end{array}$} \\
\hline & & & & & & & $\underset{\text { (a) }}{\text { PRSA-20 }}$ & $\begin{array}{l}\text { PRSA-180 } \\
\text { (b) }\end{array}$ & $\begin{array}{l}\text { Renin acti- } \\
\text { vation index } \\
a / b \times 100\end{array}$ \\
\hline & \multicolumn{9}{|c|}{ Mean } \\
\hline & \multicolumn{3}{|c|}{$\begin{array}{l}\text { Bilateral disease } \\
\text { (Subjects 6, 10, and 11) }\end{array}$} & \multicolumn{3}{|c|}{$\begin{array}{l}\text { Right R.V. } \\
\text { Left R.V. }\end{array}$} & $\begin{array}{l}1000 \\
1033\end{array}$ & $\begin{array}{l}900 \\
900\end{array}$ & $\begin{array}{l}100 \% \\
100 \%\end{array}$ \\
\hline & \multicolumn{3}{|c|}{ Unilateral disease } & \multicolumn{3}{|c|}{$\begin{array}{l}\text { More involved kidney } \\
\text { Less involved kidney }\end{array}$} & $\begin{array}{l}616 \\
337\end{array}$ & $\begin{array}{l}1506 \\
1630\end{array}$ & $\begin{array}{l}41 \% \\
21 \%\end{array}$ \\
\hline
\end{tabular}




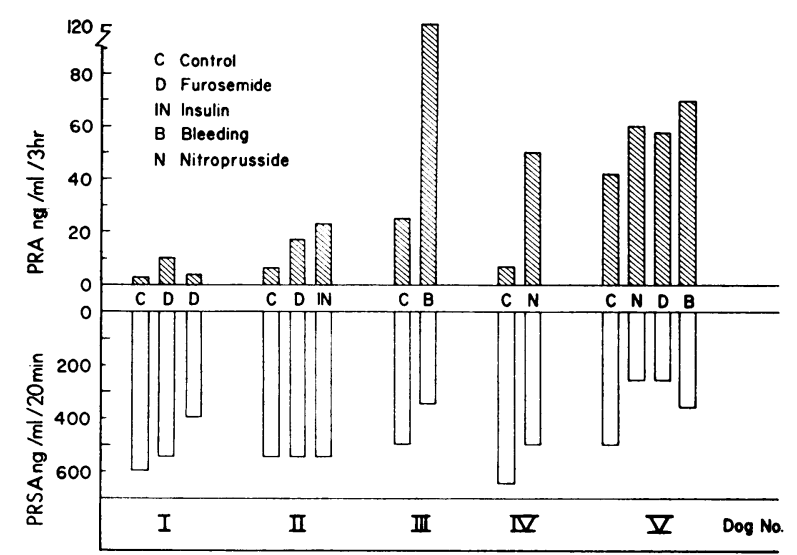

FIGURE 5 PRA expressed as nanograms angiotensin/milliliter plasma per $3 \mathrm{hr}$ incubation time (shaded columns) and PRSA as nanograms angiotensin/milliliter per 20 min (clear columns) are compared in the venous plasma obtained from five $\operatorname{dog}$ s before and after stimulation of renin release. PRSA-180 min measurements were also made in each plasma sample; and the values during the experimental periods did not differ significantly from those during the control periods.

marked degree. In none of the experiments, however, did the PRSA-20 min measurement show an increase over the control value. PRSA-180 min (not shown in Fig. 5) were also measured during all control and experimental periods but did not show appreciable changes.

Influence of plasma lipid extraction on PRSA-20 min measurements. In order to investigate if the observed differences between bilateral renal venous PRSA-20 min values in renal hypertensive patients can be attributable to the presence or the lack of factors contained in the lipid fractions of plasma, lipids were extracted from lyophilized plasma as described in the methods, and the rate of angiotensin generation with added excess of renin in the defatted and reconstituted plasma was compared with that in the whole plasma. For the purpose of these experiments, renal venous plasma samples showing bilaterally unequal PRSA-20 min values (group A, six patients) were compared with those showing insignificant bilateral difference (group B, six patients). Lipid extraction did not appreciably influence the rate of angiotensin generation in renal venous plasma samples from either group. The magnitude of bilateral difference between PRSA-20 min values in group A patients as well as the pattern of bilaterally equal renal venous PRSA values in group B subjects were both preserved when PRSA-20 min was performed in the lipid extracted renal venous plasma. Furthermore, the addition of extracted lipids to the contralateral defatted renal venous plasma samples of group A subjects failed to alter the PRSA values.

\section{DISCUSSION}

The results indicate that under the experimental conditions defined as PRSA-20 min determinations, the initial rate of angiotensin generation was generally higher in the renal venous plasma from the involved than the contralateral kidney in a group of patients suspected of suffering from renal hypertension. The studies also indicate that in the patients studied, the lateralization of PRSA-20 min is more marked than that of PRA values (Figs. 2 and 3 ). The studies further indicate that the existing bilateral differences in renal venous plasma were obliterated and the values were found to be equal on both sides when angiotensin generation was measured for longer periods of incubation (PRSA-180 min) and thus equated, under the given conditions, to the total consumable renin substrate. The expression of Renin Activation Index as defined has potential significance not only in the diagnostic differentiation between the bilateral vs. unilateral renal disease, as well as between the two kidneys in the predominantly unilateral disease, but also in understanding the mechanisms involved in the activation of renin reaction in renal hypertension. The prognostic significance, however, of unilateral increase in the initial rate of angiotensin generation (PRSA-20 min) as well as of the unilateral increase of the Renin Activation Index, in the selection of patients for surgical treatment of renal hypertension. is still under investigation. Future studies are also required to ascertain if elevated PRSA-20 min is related to the fundamental mechanisms operative in the ischemic kidney that maintain the hypertensive state.

Factors influencing in vitro generation of angiotensin in plasma have been discussed by Bumpus (24). A higher yield of angiotensin from the involved kidney's venous plasma may be ascribed to: $(a)$ a higher content of renin; $(b)$ a higher concentration of renin substrate; $(c)$ the lack of a renin inhibitor, present in the contralateral renal venous effluent; $(d)$ the presence of a "renin activating" factor or a mechanism.

In the absence of inhibitors or activators of renin, angiotensin generation during PRSA determinations as defined should depend upon the available concentration of both the enzyme and its substrate.

The experimental design and the results of the present studies tend to exclude the possibility that the existing bilateral difference of endogenous renin content of renal venous blood indicated by PRA determinations, could contribute towards the difference observed between bilateral angiotensin production during PRSA-20 min determinations. The latter differences were observed at near maximal rates of angiotensin production far in excess (a calculataed factor of 900 -fold, Fig. 2) of those observed with endogenous renin. 
Since these results were obtained by the addition of exogenous renin to bilateral renal venous plasma, they also preclude the necessity to postulate a primary change in the nature of the endogenous renin molecule secreted by the ischemic kidney. Furthermore, the animal experiments (Fig. 5) showed that even induced elevations of endogenous renin content of plasma within the biologic range do not increase the determined value of PRSA. These studies on dogs further indicated that the release of a hypothetical "activator" or the induction of an activating mechanism for renin is not related to the physiologic mechanisms of renin release.

Most of our in vitro studies were performed on whole undialysed plasma, and it may be questioned if the demonstrated bilateral renal venous difference in PRSA20 min significantly depends upon a higher content of preformed pressor materials in the plasma from the ischemic kidney $(10,25)$. Any contribution of preexisting materials in whole plasma to the values of generated angiotensin produced during PRSA-20 min determinations (range $200-1200 \mathrm{ng} / \mathrm{ml}$ plasma) becomes negligible when the comparative amounts involved are considered. Gocke, Gerten, Sherwood, and Laragh (25) demonstrated a higher content of angiotensin II in the renal venous plasma from the ischemic than the contralateral kidneys of patients with hypertension. The highest value per $1 \mathrm{ml}$ of plasma of angiotensin II detected in these studies was $1 \mathrm{ng}$. Grollman and Ebihara (10) described the presence, in the renal venous plasma from the ischemic kidney, of an "angiotensin I-like" pressor material presumably bound to protein and not subject to dialysis. The pressor effect of directly injected crude plasma considered significant in these studies ranged from 5 to $12 \mathrm{ng}$ equivalents of angiotensin II per milliliter plasma.

The influence of any preexisting pressor materials, therefore, on PRSA-20 min determinations can be discounted as insignificant. These materials, on the other hand, when present may very well account for a significant part of the difference in bilateral renal venous PRA determinations.

Since the importance of the enzyme (renin) content is mitigated by the considerations discussed earlier, the content of renin substrate in the bilateral renal venous plasma could be considered as the prime determinant of the level of angiotensin production during PRSA-20 min measurements. The results, however, do not support this assumption. Measurements of PRSA-180 min were not significantly different in bilateral renal venous plasma from patients with renal hypertension (Fig. 4, Table I).

The data presented strongly suggest that an undefined "renin activating mechanism" is originating in the ischemic kidney. The mechanism may rapidly exhaust itself in vitro and be reflected only in initial rate measurements. Experiments shown in Fig. 4 (lower panel), however, do not support this suggestion.

The possible mechnisms to be considered are: (a) elaboration of a protein activator of renin; $(b)$ induction of molecular changes in renin substrate so as to favor an acceleration of the renin reaction. Future work using methods of improved sensitivity and specificity is required.

The above considerations further suggest that the bilateral disparity of renal venous PRA determinations observed in patients with renal hypertension may not always reflect a true difference in renin content but rather depend considerably on some of the same factors discussed here that seem to determine the disparity of PRSA-20 min measurements. In this regard, however, a possible role of the contralateral "normal" kidney still remains to be elucidated. The not so infrequent finding of a renal venous PRA measurement or PRSA20 min determination (Table I) from the contralateral kidney being lower than the value obtained in plasma from the low inferior vena cava, has not been explained. Renin destruction by the contralateral kidney, elaboration of a renin inhibitor (other than extractable plasma lipids), and inactivation of a renin activator remain theoretical possibilities.

\section{ACKNOWLEDGMENTS}

This work was supported by Grant No. HE-09142 from the National Institutes of Health of the U. S. Public Health Servioe.

\section{REFERENCES}

1. Judson, W. E., and O. M. Helmer. 1965. Diagnostic and prognostic values of renin activity in renal venous plasma in renovascular hypertension. Hypertension, Proc. Counc. High Blood Pressure Res. 13: 79.

2. Genest, J., G. Y. Tremblay, R. Boucher, J. de Champlain, J. M. Rojo Ortega, R. Lefebvre, P. Roy, and P. Cartier. 1966. Diagnostic Significance of Humoral Factors in Renovascular Hypertension. In Anti-hypertensive Therapy Principles and Practice; An International Symposium ; Proceedings. F. Gross, editor. Springer-Verlag New York, Inc., New York. 518.

3. Meyer, P. H., J. Ecoiffier, J. M. Alexandre, C. Devaux, L. Guize, J. Menard, P. Biron, and P. Milliez. 1967. Prognostic value of plasma renin activity in renovascular hypertension. Circulation. 36: 570.

4. Fitz, A. 1967. Renal venous renin determinations in the diagnosis of surgically correctable hypertension. Circulation. 36: 942.

5. Michelakis, A. M., J. H. Foster, G. W. Liddle, R. K. Rhamy, O. Kuchel, and R. D. Gordon. 1967. Measurements of renin in both renal veins. Its use in diagnosis of renovascular hypertension. Arch. Intern. Med. 120: 444.

6. Amsterdam, E. A., R. Christlieb, N. P. Couch, and R. B. Hickler. 1967. Predictive value of peripheral versus renal venous activity in surgery for renovascular hypertension. Circulation. 36(Suppl. 2): 50. 
7. Amsteradam, E. A., N. P. Couch, A. R. Christlieb, J. H. Harrison, C. Crane, S. J. Dobrzinsky, and R. B. Hickler. 1969. Renal vein renin activity in the prognosis of surgery for renovascular hypertension. Amer. J. Med. $47: 860$.

8. Burgoignie, J., S. Kurz, F. J. Castazaro, P. Serirat, and H. M. Perry. 1970. Renal venous renin in hypertension. Amer. J. Med. 48: 332.

9. Bath, N. M., J. C. Gunnells, Jr., and R. R. Robinson. 1968. Plasma renin activity in renovascular hypertension. Amer. J. Med. 45: 381.

10. Grollman, A., and A. Ebihara. 1968. Comparison of the pressor activity and renin content of the renal venous effluent in patients suspected of suffering from surgically remediable hypertension. Tex. Rep. Biol. Med. 26: 313.

11. Shapiro, A. P., E. Perez-Stable, E. T. Scheib, K. Bron, S. E. Moutsos, G. Berg, and J. R. Misage, with the assistance of H. Bahnson, B. Fisher, and T. Drapanas. 1969. Renal artery stenosis and hypertension. Observations on current status of therapy from a study of 115 patients. Amer. J. Med. 47: 175 .

12. Boucher, R., R. Veyrat, J. de Champlain, and J. Genest. 1964. New procedures for measurement of human plasma angiotensin and renin activity levels. Can. Med. Ass. J. 90: 194.

13. Pickens, P. T., F. M. Bumpas, A. M. Lloyd, R. R. Smeby, and I. H. Page. 1965. Measurements of renin activity in human plasma. Circ. Res. 17: 438.

14. Poulsen, K. 1967. Microtechnique for quantitative measurement of renin in plasma. Acta Pathol. Microbiol. Scand. 69: 19.

15. Sen, S., R. R. Smeby, and F. M. Bumpus. 1967. Isolation of a phospholipid renin inhibitor from kidney. Biochemistry. 6: 1572 .
16. Ostrovsky, D., S. Sen, R. R. Smeby, and F. M. Bumpus. 1967. Chemical assay of phospholipid renin preinhibitor in canine and human blood. Circ. Res. 21: 497.

17. Osmond, D. H., R. R. Smeby, and F. M. Bumpus. 1969. Quantitative studies on renin preinhibitor and total phospholipids in organs and in plasma and erythrocytes of control, nephrectomized and very old rats. J. Lab. Clin. Med. 73: 795.

18. Gould, A. B., L. T. Skeggs, and J. R. Kahn. 1966. Measurement of renin and substrate concentrations in human serum. Lab. Invest. 15: 1802.

19. Skinner, S. L. 1967. Improved assay methods for renin "concentration" and activity in human plasma. Circ. Res. 20: 391 .

20. Sambhi, M. P., and J. D. Barrett. 1967. Development of tachyphylaxis to aspartyl ${ }^{1}$ and not to asparginyl ${ }^{1}$ angiotensin II in the rat. Circ. Res. 21: 327.

21. Haas, E., H. Goldblatt, E. C. Gipson, and L. Lewis. 1966. Extraction, purification and assay of human renin free of angiotensinase. Circ. Res. 19: 739.

22. Surgenor, D. M., L. E. Strong, H. L. Taylor, R. S. Gordon, and D. M. Gibson. 1949. The separation of choline esterase, mucoprotein and metal-combining protein into subfractions of human plasma. J. Amer. Chem. Soc. $71: 1223$.

23. Dixon, M., and E. C. Webb. 1964. Enzymes. Academic Press, Inc., New York. 950.

24. Bumpus, F. M. 1966. Factors affecting formation and destruction of angiotensin. In International Club of $\mathrm{Ar}$ terial Hypertension. First meeting. Paris, 1965. Expansion Scientifique Française, Paris. 3.

25. Gocke, D. J., J. Gerten, L. M. Sherwood, and J. H. Laragh. 1969. Physiological and pathological variations of plasma angiotensin II in man. Correlation with renin activity and sodium balance. Hypertension, Proc. Counc. High Blood Pressure Res. 17: 131. 